\title{
COUPLED THERMOMECHANICAL NUMERICAL INVESTIGATIONS OF A HOT FORGING DIE WITH AN INTEGRATED COOLING SYSTEM
}

\author{
${ }^{1}$ Bernd-Arno BEHRENS, ${ }^{1}$ Alexander CHUGREEV, ${ }^{1}$ Martin BONHAGE, \\ ${ }^{1}$ Christoph BÜDENBENDER, ${ }^{2}$ Aleksandr ZAITSEV, ${ }^{1}$ Irfan Yousaf MALIK \\ ${ }^{1}$ Institute of Forming Technology and Machines (IFUM), Leibniz University Hannover, \\ Garbsen, Germany, EU, malik@ifum.uni-hannover.de \\ 2Institute of Metallurgy, Mechanical Engineering and Transport (IMMeT), Peter the great Saint-Petersburg \\ Polytechnic University, St. Petersburg, Russian Federation
}

https://doi.org/10.37904/metal.2019.698

\section{Abstract}

Tools in hot forging processes undergo high thermal and mechanical loads and thus experience corresponding fatigues. Mechanical fatigue can be reduced by design optimization, but process related changes are needed in order to minimize the thermal fatigue. Especially the control of the ground temperature is important since it influences a large number of tool attributes e.g. strength and ductility, peak temperature and temperature difference. The use of an active cooling system allows a targeted control of the tool ground temperature thus leading to a reduction in process interruptions as well as maintenance time. In comparison to common straight drilled cooling channels, tool-specific cooling systems are known to remarkably take influence on an individual tool design, thus improving tool durability. The current study deals with the numerical investigation of a forging die with an oil based integrated cooling system. Different parameters like the coolant temperature and the mass flow rate were considered in order to evaluate the behaviour of the system during application. The results were compared with the temperature distribution in the forging die without integrated cooling. The findings of this work will help to further optimize the hot forging die and in return lead to more efficient forging processes.

Keywords: Cooling system, design optimization, forging, thermal effects, numerical study, FEM

\section{INTRODUCTION}

Powder metallurgy addresses the primary requirement of modern day manufacturing processes - higher material utilization. Ongoing research at the IFUM deal with development of a hot forging die with integrated cooling channel and a passive insert to induce a cooling effect in the mandrel by heat conduction. A schematic of this concept is shown in Figure 1.

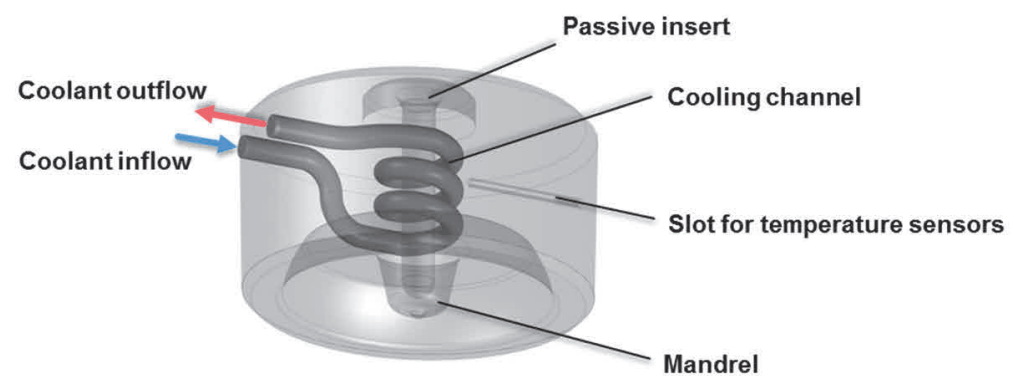

Figure 1 Schematic sketch of the forging die with integrated cooling channel

\section{STATE OF RESEARCH}

During forging processes, the tools undergo cyclic thermal as well as mechanical loads. In addition to mechanical tool failures, the temperature variations also have an influence on the die curvature and 
consequently part accuracy. Thus, tool wear as well as service life of the tools is of particular importance in these processes [1]. Primarily, the thermal state of a tool is influenced by factors like forging temperature, forming rate, amount of friction, cycle time and heat flow during convection, conduction and radiation [2]. Previous research works show that lubricants and cooling systems help against these thermal loads to keep the ground temperature steady [3]. Cooling systems tend to play a crucial role in tool life, process productivity as well as product quality. In an earlier research, Behrens et al. have shown that the wear behaviour depends on the tool surface temperature and discussed the possibility of heat pipe cooling as an alternative cooling method [4]. Hassan et al. investigated the effect of cooling channels' shape and their location on the temperature distribution of the mould. Their work showed that the position of the cooling channels has a great effect on the cooling process and the mould product [5].

In order to influence the temperature of forging dies, generally spray cooling systems are used. The cooling lubricant is applied to the outer surface of the tools between the forging cycles resulting in a high temperature gradient between surface and ground temperature. These cooling systems can be complemented by the integration of internal channels which can provide a possibility of actively influencing the basic temperature by heating and cooling. Muessig used a forging die equipped with drilled and milled cooling channels in his research and argued that the basic temperature of the die can be kept constant by means of tempered dies [2]. Investigations by Saifullah et al. show that a proper design and geometry of cooling channels adapted to the tool can reduce cooling time by $40 \%$ and total cycle time by $35 \%$, in return greatly improving the production rate as well as the quality of parts [6]. Thus, adapted cooling systems lead to advantages such as e.g. shorter cycle times, stable processes and higher accuracy. These advantages have to be taken into consideration for the design of forging dies, particularly if highest accuracy is required.

\subsection{Creation of Integrated Channels}

The proven powder metallurgy processes (cold pressing, sintering and melting out) have been considered for the production of integrated cooling channels and their drawbacks have been evaluated in an earlier research works by the authors $[7,8]$. It was observed that copper, as a low-melting metal, is suitable for the integration of channels in a metal powder matrix. The integration of copper in a steel matrix by cold pressing and sintering was seen as a suitable and time-efficient method [8]. Danninger has argued that if the solid element melts completely and infiltrates the surrounding matrix, it leaves a cavity with the exact form of the primary element [9]. The infiltration of the surrounding powder is enabled through capillary effects and can have an influence on the tool strength, since different local densities around the cavity. Crack formation by unfavourable load distribution during cold pressing as well as the cyclic loads during the forging process were identified as potential sources of error. This observation leads to a major limitation for the integration of foreign elements into a metal powder matrix for hot forging application. In order to overcome these discrepancies, laser sintering was chosen as a suitable process for the production of an individual integrated channel system. The authors have shown that high local stresses and temperatures were found in the cooling die so that the need for a further design optimization was suggested [8]. For this purpose, a detailed study to evaluate thermomechanical behaviour of the die as well as the effects of coolant is necessary, in order to study the temperature profile of the die under the influence of different process parameters. The current work presents the findings of such investigations.

\section{FLUID FLOW THROUGH CURVED CHANNELS}

Flows in curved channels have been of keen importance in the field of engineering in general and fluid mechanics in particular. The modelling of such flows is very challenging and has a considerably higher complexity than the flows in straight pipes. Due to inertia of the fluid, a secondary motion appears in addition to the primary axial fluid flow induced due to an imbalance between the cross-stream pressure gradient and the centrifugal force. Such a secondary fluid motion consists of a pair of counter-rotating vortices, which appear 
even for the most mildly curved pipe [10]. This type of fluid flow is subjected to centrifugal forces causing creation of a pressure gradient normal to the direction of the main flow which induce a pronounced and irregular spiral flow motion [11]. The presence of shear stress at the boundary of the channel leads to an abrupt decrease in the velocity, resulting in a velocity gradient in the boundary layer [12]. The asymmetry of the velocity, pressure and wall shear stress fields in curved channels relative to those arising in fully developed flows in straight pipes have been associated with increased heat transfer coefficient [13]. The coolant flow inside the cooling channels is a classic example of fluid flow through narrow curved channels, thus a consideration of this phenomenon is important in the scope of this work.

The behaviour of a fluid flowing through a channel at any given temperature depends on a number of factors, mainly velocity, density, characteristic length of the channel and the viscosity of the fluid. The influence of these parameters on the fluid behaviour is given with help of Reynolds' number which can be expressed in the form of equation (1) below.

$R e=\rho u D / \mu$

Where $\rho\left[\mathrm{kg} / \mathrm{m}^{3}\right]$ is the density, $u[\mathrm{~m} / \mathrm{s}]$ is the velocity, $\mu[\mathrm{kg} /(\mathrm{m} \cdot \mathrm{s})]$ is the dynamic viscosity of the fluid and $D[\mathrm{~m}]$ the characteristic length of the channel. At low velocities (i.e. lower Reynolds' numbers) flow is said to be laminar and the velocity profile inside the channel is streamlined uniformly whereas a higher Reynolds' number leads to a turbulent flow and exhibits a sharp velocity change near the boundary of the channel. Hence, in order to accurately capture the flow behaviour a turbulence model is needed. In the scope of this research work, the Shear Stress Transport (SST) turbulence model has been used which is a two-equation eddyviscosity model that accounts for the transport of the turbulent shear stress and gives highly accurate predictions of the amount of flow separation under adverse pressure gradient [14].

\section{NUMERICAL INVESTIGATION}

Numerical investigations play a vital role in the metal forming industry to examine the material flow as well as the behaviour of tools and parts. The Finite Element (FE) approach makes the cost-intensive and time consuming experiments redundant. Thus, a numerical investigation has been carried out to analyse the behaviour of a designed die under process relevant boundary conditions. Initially an investigation of a forging process was carried out to examine the temperature distribution in the forging die before the application of cooling. The obtained temperature profiles were later used in the study to realize the behaviour of forging die when cooling is applied.

\subsection{Evaluation of the Temperature Profiles}

An investigation of the temperature field in the die at the end of different forging cycles is necessary in order to study the influence of cooling on the temperature profile of the forging die. Thus, considering the similar FE model approach as used for the initial analysis presented in a previous work of the authors [8], a comprehensive thermo-mechanical analysis was done using the FE program simufact.forming. Figure 2 shows the FE-model for this analysis. The lower die is modelled as a rigid body. The forging die is modelled as an elasto-plastic material and assigned work tool steel DIN 1.1545. The billet (workpiece) is assigned an elasto-viscoplastic material behaviour with steel 1.0503 (DIN C45, AISI 1045). The FE mesh of the upper die has a total of 128191 elements and was refined in the lower part (mandrel and lower surface) as well as around the channel. The billet was set to have a mesh consisting of 61296 elements with a maximum element length of $1 \mathrm{~mm}$. During this analysis, the forging temperature of the workpiece (billet) was set as $1200{ }^{\circ} \mathrm{C}$. An initial temperature of $250^{\circ} \mathrm{C}$ is considered for the forging die. The heat transfer coefficient between billet and upper die was set to $50 \mathrm{~W} /\left(\mathrm{m}^{2} \cdot \mathrm{K}\right)$, a value of $420 \mathrm{~J} /(\mathrm{kg} \cdot \mathrm{K})$ is assigned to the heat capacity cp whereas the thermal conductivity is set to $46 \mathrm{~W} /(\mathrm{m} \cdot \mathrm{K})$ based on the material database of the software. On basis of the research by Jeong et al., the combined Coulomb-Tresca model is used to describe the friction with a friction coefficient 0.1 
and a friction shear factor of 0.3 [15]. The center line as well as the bottom surface was defined for the forging die. As a result of this analysis, temperature profiles on the bottom surface as well as the center line of the forging die were evaluated.
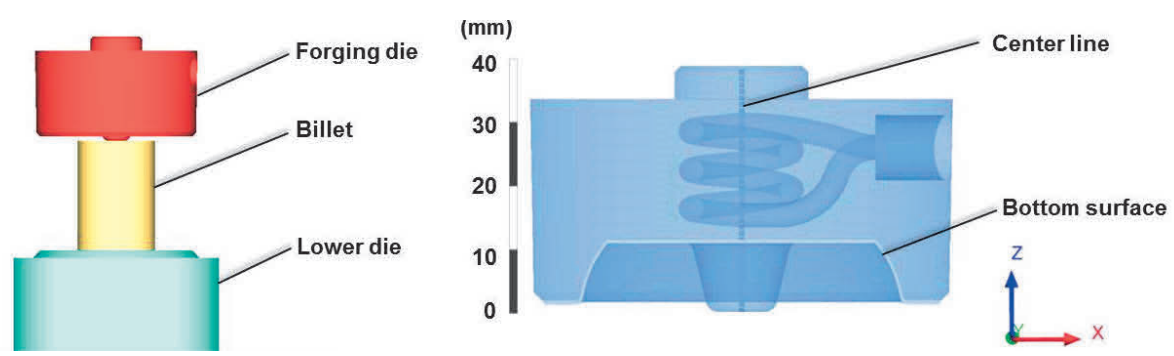

Figure 2 FE-model of the forging process (left), bottom surface as well as center line of the forging die (right)

\subsection{Investigation of the Cooling Behaviour}

A detailed investigation of the cooling system could be realized based on the evaluated above temperature fields in the die. Transient numerical simulations were carried out using the finite volume solver of commercial software ANSYS CFX for three different coolant flow rates of $0.0000283 \mathrm{~m}^{3} / \mathrm{s}(1.7 \mathrm{~L} / \mathrm{min}), 0.0000567 \mathrm{~m}^{3} / \mathrm{s}$ $(3.4 \mathrm{~L} / \mathrm{min})$ and $0.0001133 \mathrm{~m}^{3} / \mathrm{s}(6.8 \mathrm{~L} / \mathrm{min})$ at three different inlet temperatures $\left(25,100\right.$ and $\left.150{ }^{\circ} \mathrm{C}\right)$ in order to investigate the behavior of the die with cooling is applied. A single forging cycle (time period of 0.44 second) was considered. The forging die was defined as an elasto-plastic material made of tool steel 1.1545 with a temperature of $250^{\circ} \mathrm{C}$ in this model as well. Renolin therm 320 has been considered as a coolant with physical properties as mentioned in Table 1 [16]. The numerical model consists of 650356 tetra elements in total. The die comprises of 475499 elements whereas 174857 elements were assigned to the channel section (Figure 3). The mesh was refined near the channel surface to allow for capturing of boundary layer and wall effects.

Table 1 Physical properties of the coolant (Renolin therm 320)

\begin{tabular}{|c|c|c|c|c|c|}
\hline Temperature & Density & $\begin{array}{c}\text { Specific } \\
\text { Heat }\end{array}$ & $\begin{array}{c}\text { Thermal } \\
\text { Conductivity }\end{array}$ & $\begin{array}{c}\text { Kinematic } \\
\text { Viscosity }\end{array}$ & $\begin{array}{c}\text { Dynamic } \\
\text { Viscosity }\end{array}$ \\
\hline$\left({ }^{\circ} \mathrm{C}\right)$ & $\left(\mathrm{kg} / \mathrm{m}^{3}\right)$ & $(\mathrm{J} /(\mathrm{kg} \cdot \mathrm{K}))$ & $(\mathrm{W} /(\mathrm{m} \cdot \mathrm{K}))$ & $\left(\mathrm{m}^{2} / \mathrm{s}\right)$ & $(\mathrm{kg} /(\mathrm{m} \cdot \mathrm{s}))$ \\
\hline 25 & 863 & 1910 & 0.1325 & 0.0002818 & 0.2433 \\
\hline 100 & 816 & 2293 & 0.127 & 0.0000065 & 0.0053 \\
\hline 150 & 783 & 2507 & 0.12 & 0.0000015 & 0.0011 \\
\hline
\end{tabular}

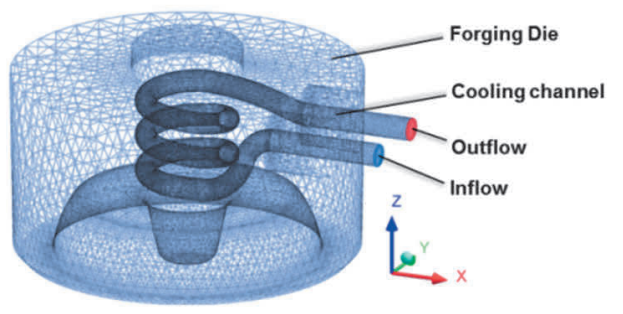

Figure 3 ANSYS CFX mesh for the die and the cooling channels

The investigations showed that with an increasing mass flow rate, there is a considerable decrease in the temperature of the die in the region next to the cooling channel (Figure 4). The cooling channel is located at a distance of $14 \mathrm{~mm}$ from the base of the mandrel and is $16 \mathrm{~mm}$ in height. The effect of the cooling process starts to become visible in the zone between $12.5 \mathrm{~mm}$ and $14 \mathrm{~mm}$ whereas, the region between $14 \mathrm{~mm}$ and 
$30 \mathrm{~mm}$ is directly affected by the cooling. The highest temperature values exist at the lower part of the mandrel for all the considered mass flow rates. This is due to the fact that the mandrel has direct contact with the hot workpiece and thus because of heat conduction the mandrel experiences a continuous thermal loading throughout the process. It can be observed that the effects of the cooling channel do not reach this region.

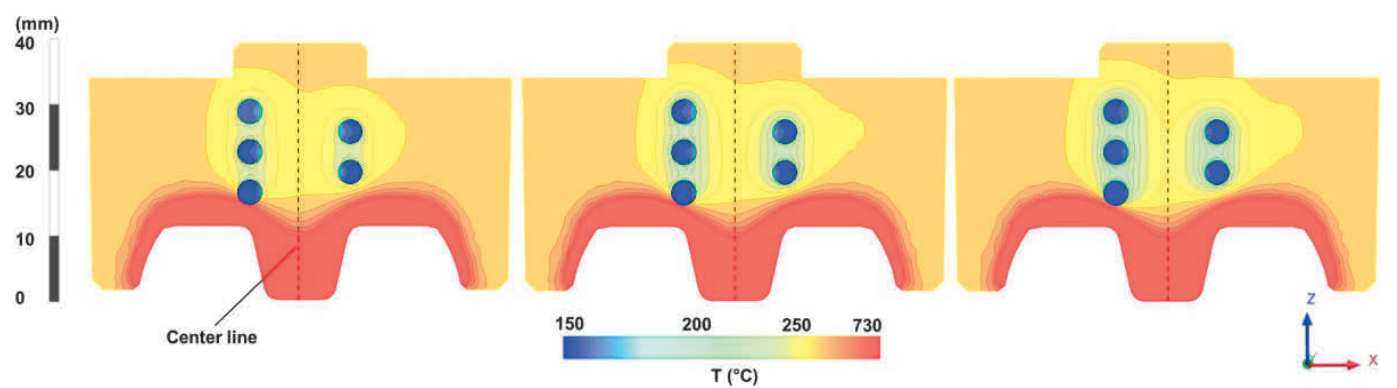

Figure 4 Contours of temperature distribution in the forging die with different coolant flow rates. Left: $0.000028 \mathrm{~m}^{3} / \mathrm{s}(1.7 \mathrm{~L} / \mathrm{min})$, Center: $0.000057 \mathrm{~m}^{3} / \mathrm{s}(3.4 \mathrm{~L} / \mathrm{min})$ and Right: $0.000113 \mathrm{~m}^{3} / \mathrm{s}(6.8 \mathrm{~L} / \mathrm{min})$ (coolant temperature $150^{\circ} \mathrm{C}$ )

Figure 5 (left) provides a comparison of the temperature distribution along the entire center line of the die with cooling channel for different mass flow rates with the temperature profile of a die without cooling. The curves for all the mass flow rates seem to overlap. This is due to the fact that the considered time period of 0.44 seconds is too small for any enormous effects of mass flow to become visible. Nevertheless, the mass flow rate has an influence on the cooling effect for the region with cooling channel as shown in the Figure $\mathbf{5}$ (right). It was observed that the temperature of the die decreases with a higher mass flow rate albeit just a few degrees. Hence, it can be argued that higher time periods and forging cycles can provide a further insight into the process.
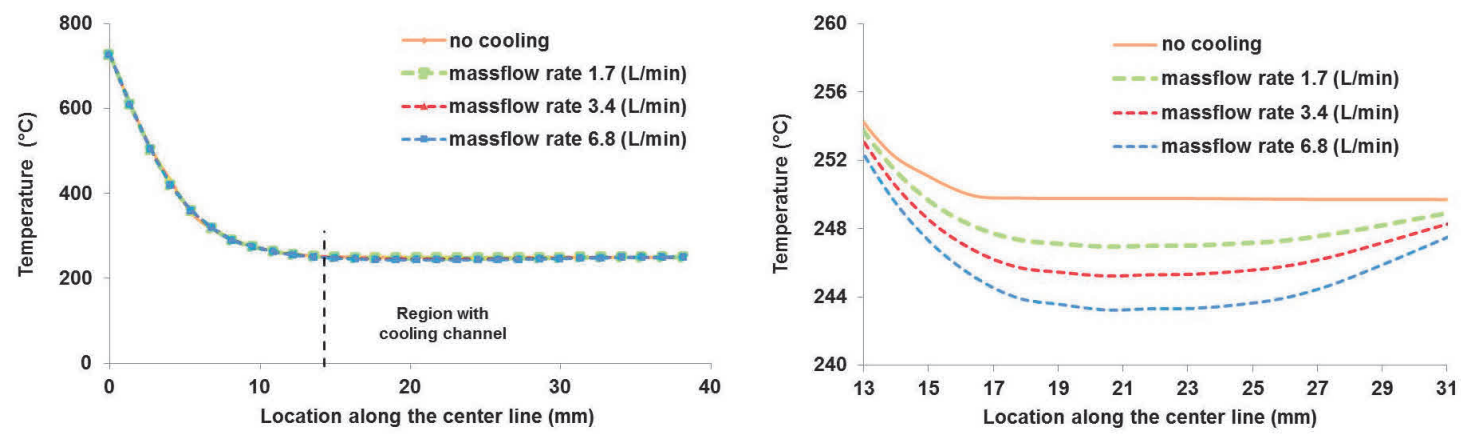

Figure 5 Temperature profile along the center line of the forging die with and without cooling influence: along the entire height of the die (left) and in the region with the cooling channels (right)

\section{CONCLUSION AND OUTLOOK}

In this work, numerical investigations have been carried out to analyse the effects of cooling channel based on process parameters like coolant temperature as well as mass flow rate for one forging cycle. Based on the results of the current work and previously concluded research during the scope of CRC653, it has been concluded that the cooling system strongly influences the region in the die center. The effects of the coolant mass flow rate depend on the time period of the process or number of forging cycles thus an investigation with higher time periods is in consideration. As the mandrel experiences a noticeable increase in temperature due to heat conduction, a vertical passive insert as shown in the schematic sketch (Figure 1) has to be drilled in the die as a passive insert. Moreover, considering that the mandrel and lower surface experience the highest 
temperatures and thus are more pertaining to undergo a wear, a cooling modular tool layout is being developed in order to avoid the higher manufacture costs of channels.

\section{ACKNOWLEDGEMENTS}

The presented results are based on the framework of the research projects Collaborative Research Center 653 "Gentelligent Components in their Lifecycle" in the subproject E3 "Sintering gentelligent parts from metal powder" (grant number 5486368) and "Development of a geometry based method for the compensation of process-related dimensional deviations of solid formed parts" under the (grant number 334525444). The authors would like to thank the German Research Foundation (DFG) for the financial support.

\section{REFERENCES}

[1] ABACHI, S., AKKÖK, M. and GÖKLER, M. İ. Wear analysis of hot forging dies. Tribology International. 2010. vol. 43, pp. 467-473.

[2] MÜSSIG, B. Temperierung von Schmiedewerkzeugen zur Erhöhung der Bauteilgenauigkeit. Dissertation. Leibniz Universität Hannover, 2002 in German.

[3] SEIDEL, R. Reduzierung der thermischen Schädigung von Schmiedewerkzeugen durch Kühlschmierung. Fortschritt-Berichte VDI, Fertigungstechnik, 1996. 399 in German.

[4] BEHRENS, B.-A., PUPPA, J., HUSKIC, A., BRUNOTTE, K., BOUGUECHA, A. and PRÜSS, T. Influence of heat pipe cooling on the wear of hot forging dies. Production Engineering. 2016. vol. 10, pp. 599-606.

[5] HASSAN, H., REGNIER, N., CEDRIC, L., CYRIL, P. and GUY, D. Effect of cooling system on the polymer temperature and solidification during injection molding. Applied Thermal Engineering. 2009. vol. 29, pp. 17861791.

[6] SAIFULLAH, A. B. M. and MASOOD, S. H. Cycle time reduction in injection moulding with conformal cooling channels. In Proceedings of the International Conference on Mechanical Engineering 2007 (ICME07-AM-42), 2931 December 2007, Dhaka, Bangladesh.

[7] BEHRENS, B.-A., BOUGUECHA, A., VUCETIC, M., BONHAGE, M. and MALIK, I.Y. Compaction of a copper spiral within a cylindrical die of steel powder and investigation of their deformation behavior. In Conference Proceedings of the World PM 2016 congress and exhibition, 09-13.10.2016, Hamburg, Germany.

[8] BEHRENS, B.-A., BOUGUECHA, A., VUCETIC, M., BONHAGE, M. and MALIK, I.Y. Numerical investigation for the design of a hot forging die with integrated cooling channels. Procedia Technology. 2016. vol. 26, pp. 51-58.

[9] DANNINGER, H. Homogenization and pore formation during sintering with transient liquid phase. Powder metallurgy international. 1988. vol. 20, pp. 21-25.

[10] ARADA, N., PIRES, M. and SEQUEIRA, A. Viscosity effects on flows of generalized Newtonian fluids through curved pipes. Computers and mathematics with applications. 2007. vol. 53, pp. 625-646.

[11] DEAN, W. Fluid motion in a curved channel. Proceedings of the royal society of London, Series A, Papers of a mathematical and physical character. 1928. vol. 121, pp. 402-420.

[12] KHURI, S. A. Stokes flow in curved channels. Journal of Computational and Applied Mathematics. 2006. vol. 187(2), pp. 171-191.

[13] GALDI, G. P. and ROBERTSON, A. M. On flow of a navier stokes fluid in curved pipes. Part I: steady flow. Applied Mathematics Letters. 2005. vol.18, pp. 1116-1124.

[14] MENTER, F. R. Two equation eddy viscosity turbulence models for engineering applications. AIAA Journal. 1994. vol. 32, pp. 1598-1605.

[15] JEONG, D.J., KIM, D.J., KIM, J.H., KIM, B.M. and DEAN, T.A. Effects of surface treatments and lubricants for warm forging die life. Journal of Materials Processing Technology. 2001. vol. 113, pp. 544-550.

[16] Information on http://www.lukoilmarine.com/products/group/6/, Retrieved on 16.03.2019, 14:30 CET 